\title{
Exploring the perception of nursing students about consequences of reflection in clinical settings
}

\author{
Shahnaz Karimi ${ }^{1}$, Fariba Haghani ${ }^{2}$, Nikoo Yamani ${ }^{3}$, Majid Najafi Kalyani ${ }^{4}$
}

${ }^{1}$ Ph.D. Student of Medical Education, Department of Medical Education, Medical Education Research Center, Isfahan University of Medical Sciences, Isfahan, Iran

${ }^{2}$ Ph.D. in Curriculum Planning, Associate Professor, Department of Medical Education, Medical Education Research Center, Isfahan University of Medical Sciences, Isfahan, Iran

${ }^{3}$ MD, MSc, Ph.D. in Curriculum Planning, Associate Professor, Department of Medical Education, Medical Education Research Center, Isfahan University of Medical Sciences, Isfahan, Iran

${ }^{4}$ Ph.D. in Nursing Education, Assistant Professor, School of Nursing, Fasa University of Medical Sciences, Fasa, Iran

\section{Type of article: Original}

\begin{abstract}
Background: Reflection on practical experiences is a key element that enables students to recognize their own strengths and weaknesses and develop nursing skills. Whilst reflection may enhance students' learning in practice, there is little evidence about nursing students' perception of the consequences of reflection in clinical settings.

Objective: This study aimed to explore Iranian nursing students' perception regarding the consequences of reflection during clinical practices.

Methods: This qualitative study was conducted by a conventional content analysis approach in two nursing schools at Shiraz and Fasa Universities of Medical Sciences in Iran. Data were collected through in-depth semistructured interviews during 2015-2016, from 20 students selected by purposive sampling. All the interviews were tape-recorded, transcribed verbatim, and analyzed by content analysis method. Rigor of this study was approved by member check and external audit.

Results: Two categories emerged from the data analysis, including movement toward professionalism and selfactualization of emotions. The former consisted of three subcategories of function modification, sharing experiences and generalizing experiences. The latter consisted of two subcategories of inner satisfaction and peace of mind.

Conclusion: The results indicated that nursing students' reflection in clinical settings is effective in personal and professional levels. Reflection in a personal level led to positive emotions that increased the quality of care in patients. Accordingly, nursing educators need to create a nurturing climate as well as supporting reflective behaviors of nursing students.
\end{abstract}

Keywords: Reflection; Nursing; Student; Clinical Practicum; Qualitative Study

\section{Introduction}

Today, nurses deal with a very complex, dynamic and ever-changing system while performing a wide range of health care services (1). In order to deal with these changes, nursing students need to improve their learning in clinical practices $(2,3)$. Reflection is known as the cornerstone of learning from experience with integration of knowledge and practice $(4,5)$. Many educators recommended that trainers should prepare students for reflection on practical experiences in order to deal with the current challenges in the clinical setting (6). Reflection is a broad, ambiguous concept and there is no consensus on its definition (7). Overall, through reflection, students can observe

\section{Corresponding author:}

Associate Professor Dr. Fariba Haghani, Department of Medical Education, Medical Education Research Center, Isfahan University of Medical Sciences, Isfahan, Iran.

Tel: +98.3136688789, Fax: +98.3136688323, Email: fariba.haghani@gmail.com

Received: March 02, 2017, Accepted: June 12, 2017, Published: September 2017

iThenticate screening: June 05, 2017, English editing: August 12, 2017, Quality control: August 26, 2017

This article has been reviewed / commented by three experts

(C) 2017 The Authors. This is an open access article under the terms of the Creative Commons Attribution-NonCommercialNoDerivs License, which permits use and distribution in any medium, provided the original work is properly cited, the use is non-commercial and no modifications or adaptations are made. 
themselves within the experience framework in which they live and focus on it, thus resolving the contradictions in their practices (8). Reflection on clinical experiences by nursing students during the process of clinical learning, plays an important role in developing the capabilities of such students (9). In Iran, reflection is a concept close to religious and cultural domains. Accordingly, the concept of reflection can be traced in sayings by great religious figures such as "an hour of reflection that adds to one's knowledge is superior to seventy years of worship without thinking". Reflection in Islam has been emphasized and encouraged. Islam invites people in different ways and under various interpretations to reflect upon various areas of natural phenomena, one's self, history, and human relations, as well as interactions they have with each other (10). Several remarks by great figures in this regard represent a reflection on daily activities and attempt to improve in all aspects of life and professional career. For many years, there has been a gap between theory and practice in nursing students' clinical education (11-13). Researchers believe that reflection strives to close the gap between knowledge and practice, and converts each experience to a potential experiential learning, for the ultimate purpose of increasing quality of care for the served population (14-16). According to the findings of some studies, reflection leads to outcomes such as improving relationships between students and instructors, bridging the theory-practice gap, deep learning and strengthening the meta-cognitive skills $(17,18)$. Despite the fact that reflection has emerged in nursing literature from many years ago, and that it is regarded as an educational need in the nursing profession, which enhances the learners' knowledge and awareness, this area nevertheless, needs a deeper inspection (6). Research carried out in Iran has indicated that nursing students do not often provide the required care for patients at the bedside, which reflects the theory-practice gap $(19,20)$. In recent years, the significant gap between learning activities and clinical nursing services have led to a crisis in nursing care and raised criticism upon the nurses regarding their poor quality of patient care from the people of Iran (21). Therefore, it is necessary to identify the nursing students' perception of reflection consequences, to provide a clearer picture of the implications of reflection for running more effective programs. Determining the consequences of reflection can create a clinical education program to prevent the gap between theory and practice. Most studies on reflection have used a quantitative method; few have employed a qualitative approach in Iran. There is no qualitative study on consequences of reflection by nursing students in Iran. Due to the social, cultural, and educational differences in Iran, the present study was conducted to qualitatively explore nursing students` perception of the reflection consequences in the clinical settings.

\section{Material and Methods}

\subsection{Study Design}

This paper is part of a larger, grounded study focusing around the process of reflection at two schools of nursing (Fasa and Shiraz) in Iran. Shiraz and Fasa are among the cities in Fars Province located in southwestern Iran. Schools of Nursing in Shiraz and Fasa have a history of more than five decades and three decades in undergraduate nursing education, respectively. This part of the study seeks to reveal implications obtained in cases where nursing students act during a clinical course to reflect on their own experiences during 2015-2016. This study was conducted with a qualitative method using conventional content analysis approach. The design is appropriate for this study because it allows the participants to describe their experiences on reflection outcomes in a clinical setting in their own words.

\subsection{Participants}

The key informants consisted of 20 students (12 females and 8 males, with a mean age of 22.3 years) from two nursing schools (Shiraz and Fasa) in Iran. The students were in the 2nd to 8th semesters of a 4-year undergraduate nursing program. The inclusion criteria were having at least one semester practical training and being interested in participating and recounting experiences in the study. Sampling started with purposive sampling method with maximum variation (e.g., variation in genders, regarding semester, average level and marital status) and continued with theoretical sampling.

\subsection{Data collection}

Data were collected using in-depth, semi-structured interviews. Following a written consent document, face to face interviews were conducted by one of the authors (SK.) in a convenient place and at a suitable time on the willingness of the participants, from February through November, 2016. The duration of the interviews varied from 45 to 90 minutes; on average, they lasted 60 minutes. The interview guide was designed with key questions to explore the experiences of the participants in detail. At the beginning of the interviews, some warm-up and general questions were asked to greet the participants in an informal manner to get acquainted with them and receive useful information about their experiences; then, more specific questions were asked to the aim of the research. The openended questions focus on the experience of reflection in a clinical setting, and subjective perceived outcome related 
to reflection as follows: Tell me about one of your clinical experiences that you had to think and reflect more? What leads you to reflect on these experiences? What was the consequence of this reflection on your clinical experience? Who helped you to achieve these consequences? In the following part, probing questions were used to provide future details or clarification during the interview according to the participant's responses, such as could you explain about it more? Can you give me an example? At the end, one open question was asked to discover details that might not have been unveiled, such as "Do you want to add anything more?" The sampling continued until data saturation was reached and when all categories and subcategories were made and no new codes or categories were added.

\subsection{Data analysis}

Data analysis was conducted using qualitative content analysis with a conventional approach. After each interview, the contents were handwritten and typed. Each transcript was checked for accuracy against the tapes. For immersion in data, the researcher to the transcripts read them several times to gain a sense of the content. In the second stage, words, sentences, or paragraphs pertinent to the outcomes of reflection on experience were selected from the statements and described as meaning units. Then, the condensed meaning units were abstracted and labeled with a code, which constituted the manifest content. Different codes were compared based on differences and similarities. Different categories were sorted into potential sub-categories and categories, and collated all the relevant coded data extracts within the identified categories. All the collated extracts were read for emerging categories and considered whether they appeared to form a meaningful and coherent pattern. Then, the validity of the individual categories in relation to the dataset, and whether our candidate categories "accurately" reflected the meaning evident in the dataset, as a whole, was considered. All authors independently examined the data for the categories. Finally, categories were named and the content of each category was paraphrased, clearly defined and refined into new categories.

\subsection{Trustworthiness}

Trustworthiness of the data was examined using the criteria of Lincoln and Guba, such as confirmability, credibility, dependability and transferability (22). Credibility of the findings was done through appropriate interaction with the participants, long-term involvement of the researcher in the research and maximum variation of sampling. Confirmability was examined by an external checker familiar with qualitative research. For this purpose, the extracted codes and categories were presented to two colleagues, and their appropriateness was controlled, verified and consensus was achieved in this regard. Member check was used to confirm whether the researchers' interpretation of the interview data was congruent with what the participants intended to express. For dependability, the researcher accurately recorded and reported the research process to allow for follow-up research by others.

\subsection{Ethical considerations}

The present study was approved by the Ethics Committee of Isfahan University of Medical Sciences (IR.MUI.REC.1395.3.054). All the participants were told about the aim of qualitative research project. The participants were ensured that participation was voluntary and that they were free to withdraw from participation at any time. It was stressed that personal data would be handled confidentially. All the participants consented to participate. The information about informed consent was given at the beginning of the interview.

\section{Results}

The results of this study are obtained based on the process of students' reflection on their clinical experiences. A total of 24 interviews were conducted with 20 nursing students, of whom eight were males and the rest were females. The students participating in this study had an average age of 22.3, were enrolling in undergraduate nursing programs (passing their second to eighth semester) and had internship experience in various sectors of hospitals of Fasa and Shiraz University of Medical Sciences. Data analysis resulted in the extraction of the classes "Movement toward professionalism" and "Self-actualization of emotions ", which, along with the basic classes, are presented in Table 1. In this section, in addition to describing the extracted classes, a detailed discussion of them is presented.

Table 1. List of main themes and sub-categories extracted from the data

\begin{tabular}{|l|l|}
\hline Main themes & Sub-categories \\
\hline Movement toward professionalism & Function modification \\
\cline { 2 - 2 } & Sharing experiences \\
\cline { 2 - 2 } & Generalizing experiences \\
\hline Self-actualization of emotions & Inner satisfaction \\
\cline { 2 - 2 } & Peace of mind \\
\hline
\end{tabular}




\subsection{Movement toward professionalization}

Experiences of the participants indicated that reflection can play an important role in increasing their ability to provide nursing care and hence making them more professional. "Movement toward professionalization" is the result of the subcategories of "Function modification", "generalizing experiences" and "sharing experiences".

\subsubsection{Function modification}

The nursing students participating in the study admitted that reflection on their clinical experiences and measures taken to alleviate their weaknesses caused their mental structure and caring behavior to change, making them able to provide efficient clinical care. One of the participants reflecting on the experience of instructing a patient on how to inject insulin described the outcome of this reflection as follows: "...I used to rely on my instructor while training the patients on how to inject insulin. I liked to keep away the doubt in my ability to individually train the patients. I reviewed several times all the past stories and experiences to myself to see what my problem is. Now, I train them so well and my trainer also approves me... (P19)". Students admitted that reflection on clinical experiences leads to high accuracy in doing clinical practices; optimal and deliberate care; quick action in providing caring services and reduced clinical errors during nursing care. In this regard, one of the students with the experience of reflection on experienced situations of writing nursing reports stated that: "...My nursing reports at the beginning were imperfect despite the great time I spent on preparing them carefully. I corrected the mistakes several times until I learned how to accurately and properly write and prepare the reports ... (P17) " The students' reflection on clinical experiences has led to increased quality of caring services. For example, a student who reflected on the experience of caring for patients with drug toxicity stated regarding the outcome of his reflection: "...I was very nervous the first time I had patients with drug toxicity problem; I was anxious. I reviewed the scene in my mind many times when I went home so I could control myself and make use of my knowledge while dealing with such patients, confidently ask and report about their backgrounds and perform necessary nursing measures... (P10) "

\subsubsection{Sharing experiences}

Regarding the cases in which experiences were reflected upon, the students acknowledged that reflective thinking has led them not only to strive to provide the right care at the bedside, but helped them to share their learning outcomes with classmates to provide further caring for patients, which in turn, leads to the development of learning. They acknowledged that they also share some relevant findings to protect their own families. One of the students said: "...Imipenem given to the patient had deposited in the microset. When I asked for the reason, they said that the drug has deposited. I have this question that if a drug is supposed to deposit, so how does it work and affect the illness. My mind was still preoccupied with the idea even after the internship. So, I searched for the reason and realized that the drug should be well shaken until it becomes completely transparent. This was because the drug is among antibiotics and this method of medication prevented the recovery process of the patient. Since then, I prepared a note on how to use imipenem and put it in the drug shelf for maintaining the drugs. In this way, I tried to inform both the nursing personnel and rest of my classmates, since this is not something that can be simply ignored as it deals with the patients' health... (P15) " Another participant who expressed her reflection on the experience of a rare case of Guillain-Barre stated regarding the implications of reflection: "...My sister is also a nurse, so I explained to her the rare case of Guillain-Barre so that she also recognized it and knew how such patients should receive nursing care..."

\subsubsection{Generalizing experiences}

The students participating in this study stated that their reflection on clinical experiences resulted in the transfer of their experiences to other clinical situations. For example, a student who had experience of reflection on the need of patients for psychological support stated the outcome of reflection on his experience as follows: "... Now during the internship, whatever I want to do for patients is mostly focused on being with them and providing them with psychological support rather than just focusing on doing nursing procedures ... (P6) " The students declared that reflection on clinical experiences resulted in the expansion of the information, success in carrying out similar activities, responding in new situations, resolving similar problems and applying scientific principles in practice. In this regard, one of the students who reflected on the experience of methods to carry out invasive procedures in clinical practice, stated about the implications of such reflection: "...When performing heparin-lock procedures, I did not care, and some sterile parts of the equipment contacted the patient's bed. The instructor gave me feedback. I was worried for a while that the patient might be affected due to my careless performance. Currently, I greatly pay attention to sterile processing while doing all invasive procedures and in all sections ... (P2) "

\subsection{Self-actualization of emotions}

The participants indicated that reflection was effective in decreasing their anxiety, uncertainty and negative emotions, helping them to reach a satisfaction with their job and achieving peace as a result of reflection. This concept was realized with two subcategories of "inner satisfaction" and "peace of mind". 


\subsubsection{Inner satisfaction}

Among the outcomes of the students' reflection are happiness, a sense of maturity, a sense of usefulness, emotional acceptance of patients, and development of positive feelings. In this regard, one of the participants said: "...Reflecting on the past and learning from my experiences give me energy, make me perform high-quality work at the bedside of the patient, and function better in practice. These all totally make me feel good ... (P5) " Another participant said: "...I now have a sense of sophistication as I have fixed my flaws and I am happy that I have managed to do nursing care so that it is effective in the recovery process of the patient... (P18) "Further, another participant said: "...I have a good feeling whenever I go to the patient's bed with high awareness; I feel confident. I feel that my presence is useful for the patient ... (P17) " Yet, another participant said: "...It is more enjoyable to me when I provide caring services at the patient's bedside with sufficient knowledge, and, thus, deliver optimal care... (P2) " Another participant stated about reflection on his experiences in relation to the outcome of the emotional acceptance of the patient: "...I feel good about my patients; I feel they are a part of me ... (P18) "

\subsubsection{Peace of mind}

The students stated the outcomes of their reflection on the experienced clinical situations in the form of reducing anxiety, decreasing distress, keeping away from the instability in caring behavior, feeling of encouraging, and achieving peace. As to the resolving concerns and achieving peace as a result of reflection, one of the students said: "...I am less anxious and feel at peace while performing similar caring services... (P1) " About distancing from the instability in caring behavior and achieving peace, another student said: "...Previously, I was concerned and alarmed while caring for the patients; I was afraid of exposing the patient to danger through my ill performance. These all disturbed me and caused me not to be able to perform my duties well. Reflecting on what I usually do was a good approach that helped me to gain confidence, stability and peace in the job... (P15) " In this regard, another participant said: "...What I do is not the routines anymore; this reduces my concerns... (P3) "

\section{Discussion}

Data analysis showed that reflection is an issue with a wide range which influences a variety of nursing practices at two levels of personal and professional. At the personal level, reflection leads to positive feelings such as satisfaction, happiness and self-confidence; thus, it motivates the nursing students more to provide health care services. According to Fernandez et al., the act of reflection is an emotional event, an event where complex cognitive processes are shaped by emotional experiences within the framework of providing nursing care services (23). Branch believes that reflection, to the extent that cognitively influences the learners' abilities, equally leads to the development of an individual in various aspects of ethics, personality, psychology and emotion (24). Notably, the majority of research on reflection has considered the product of reflection as a deep learning management following enhancing knowledge and cognitive skills $(25,26)$. A review of various studies shows that instructors, in planning interactive activities for students, are more looking for learning cognitive outcomes $(27,28)$. Therefore, emotional aspects of learning and positive emotions obtained by expression of the inner-self are generally ignored or less considered (29). One of the reflection steps according to the various presented models, is the expression of feelings $(30,31)$. However, in these models, the focus is on the emotions involved with challenges experienced and in need of being managed (32). In other words, expression of feelings and focus on emotions associated with experience is the growing factor and catalyst of reflection. Moreover, reflection based on the current study can help to grow positive feeling and emotions. The findings of this study support the value of reflection for students in reducing anxiety and creating a sense of relief, which has a positive effect on students' mental health. When the students realized a more effective role in caring for the patient following reflection, they had the feeling of usefulness which was influential on the achievement of a sense of relief and serenity in them. Rogers in his study described the emotional outcomes of reflection to include increased change of emotions, attitudes and values (33). Hsiang also showed that anxiety is reduced following self-reflection along with clinical insight and experience, leading to the development of competence of nurses in real clinical environments (34). According to a study conducted by Okuda and Fukada on nine nurses, a correlation was observed between reflection, mental growth of nurses and development of professionalism; also, it was shown that mental health enhances through reflection (35). Thus, when nursing students, in the tense clinical learning environment, find a reflection opportunity and become successful in their work, they gain a feeling of effectiveness and usefulness and are provided with the basic need of having peace. Achieving peace of mind leads to mental health and personal growth, which in turn may lead to an impact on the quality of nursing services. At the professional level, results of this study show that the reflective students place the patient at the center of care, use reflection on their experiences to provide accurate, proper and quality caring services. Here, the students expressed that reflection on clinical experiences, by reducing errors, resulted in appropriate performance of nursing activities and increased quality of care for patients. According to the study by Silva Mamedi et al., non-interactive approaches during the diagnostic reasoning process may result in 
errors; however, no evidence has been provided in connection with the interactive approach and reducing diagnostic error (36). Today, nursing has entered a period of rapid global change, which needs definite educational support to enhance the role of nurses in the field of health (37). Thus, changing and complex clinical situations require nursing educators to use teaching methods that facilitate and enhance the quality of caring services. Among other outcomes of reflection on clinical experience in nursing students, is sharing of experiences. The students, due to having concerns for the health of patients, shared the results of reflection related to optimal care with others in order to prevent incidence of clinical errors or damage to the patient and in this way, they not only intended to protect patients, but had the intention to provide immunity to their classmates against clinical errors. The results of this study showed that the quality of care does not merely mean patient care; it also includes care for self and other nursing students by sharing the outcomes of reflection on the experiences. The results of numerous studies have also widely recognized the share of nursing in achieving high quality outcomes for patients $(38,39)$. Accordingly, the results of the study by Hojjati et al. showed that the support of an educator is not sufficient alone to enhance learning, and extensive cooperation and involvement in reflection on the processes and results are more critical (40). In other studies, the issue of sharing experiences as the result of reflection has been less considered. Based on the findings of the preset study, the process of reflection has led them to actively cooperate and interact with each other and help each other during the learning procedure. Sharing experiences leads to improved caring performance and learning. Moreover, helping each other makes the clinical setting a driving environment which increases individual satisfaction. Therefore, encouragement to share the reflection outcomes among nursing students, is essential to improve the quality of health care and should be taken into account by nursing managers and policy makers. The students mentioned that they generalized the results of their reflection on clinical situations to other situations in the clinical setting and applied them in practice. In this regard, Mackglin states that reflection on experience has a huge impact on improving the ability of surgeons to deal with similar experiences in the future, and leads to the patients' health (41). Thus, by reflecting on clinical experiences, students seek to access knowledge that can be applicable in different clinical situations. Accordingly, if Dewey once regarded learning as the combination of experience and reflection (42), now one must say that learning is a process that involves a combination of experience, reflection on experience, and use of the obtained results in other related situations. Generalization and application of the results of reflecting on experiences in other clinical situations lead to strengthening and consolidation of the student's knowledge and improved the quality of health care services. This research was conducted among nursing students of just two universities, so its findings are not intended to be generalized to other settings. It is recommended that further studies be conducted in other nursing schools and other students.

\section{Conclusions}

The results obtained in this study showed that reflection in the clinical learning environment leads to personal and professional development of students. Reflection on experiences by students provides the grounds for the formation of inner positive feelings and modification of professional behavior. The results of this study can be used to develop educational interventions in order to improve clinical learning among nursing students. In inclusion of reflection in the curriculum, psychological development of students should also be noted. According to this study, performance and learning depend both on reflective behavior and behaviors related to sharing the results of reflective behavior as well as its generalization, as can be further studied in future research. According to this study, reflection on clinical experiences is very effective in establishing an infrastructure to move towards the transfer and sharing of knowledge. The present study was limited to the experience of nursing students of just two universities; thus, its findings are not intended to be generalized to other students or universities.

\section{Acknowledgments:}

This study is a part of a Ph.D. dissertation by the first author that is approved in the Department of Medical Education Research Center in Isfahan University of Medical Sciences and Health Services, Iran (Reg. 395054). The researchers acknowledge the congenial contributions from the students who participated in this study.

\section{Conflict of Interest:}

There is no conflict of interest to be declared.

\section{Authors' contributions:}

All authors contributed to this project and article equally. All authors read and approved the final manuscript. 


\section{References:}

1) Salmond SW, Echevarria M. Healthcare Transformation and Changing Roles for Nursing. Orthopedic nursing. 2017; 36(1): 12-25. doi: 10.1097/NOR.0000000000000308. PMID: 28107295, PMCID: PMC5266427.

2) Shivers E, Hasson F, Slater P. Pre-registration nursing student's quality of practice learning: Clinical learning environment inventory (actual) questionnaire. Nurse Educ Today. 2017; 55: 58-64. doi: 10.1016/j.nedt.2017.05.004. PMID: 28528125.

3) Phuma-Ngaiyaye E, Bvumbwe T, Chipeta MC. Using preceptors to improve nursing students' clinical learning outcomes: A Malawian students' perspective. International Journal of Nursing Sciences. 2017; 4(2): 164-8. doi: 10.1016/j.ijnss.2017.03.001.

4) Paterson C, Chapman J. Enhancing skills of critical reflection to evidence learning in professional practice. Phys Ther Sport. 2013; 14(3): 133-8. doi: 10.1016/j.ptsp.2013.03.004. PMID: 23643448.

5) Karimi S, Haghani F, Yamani N, Najafi Kalyani M. A Qualitative Inquiry into Nursing Students' Experience of Facilitating Reflection in Clinical Setting. Scientific World Journal. 2017. doi: 10.1155/2017/6293878. PMID: 28474003, PMCID: PMC5394401.

6) Mann K, Gordon J, MacLeod A. Reflection and reflective practice in health professions education: a systematic review. Adv Health Sci Educ Theory Pract. 2009; 14(4): 595-621. doi: 10.1007/s10459-0079090-2. PMID: 18034364.

7) Clarà M. What is reflection? Looking for clarity in an ambiguous notion. Journal of Teacher Education. 2015; 66(3): 261-71. doi: 10.1177/0022487114552028.

8) Johns C. Becoming a Reflective Practitioner A reflective and holistic approach to clinical nursing, practice development and clinical supervision. 2000.

9) Vaz DR, Prado C. Pedagogical reflective practice of nursing undergraduates: the portfolio as an instrument. Rev Esc Enferm USP. 2014; 48(6): 1103-10. doi: 10.1590/S0080-623420140000700019. PMID: 25626511.

10) Keshavarz S. Quran point of view on dimensions of reflection and its indications in education system. Procedia-Social and Behavioral Sciences. 2010; 9: 1812-4. doi: 10.1016/j.sbspro.2010.12.405.

11) Ajani K, Moez S. Gap between knowledge and practice in nursing. Procedia-Social and Behavioral Sciences. 2011; 15: 3927-31. doi: 10.1016/j.sbspro.2011.04.396.

12) Saifan A, AbuRuz ME, Masa'deh R. Theory Practice Gaps in Nursing Education: A Qualitative Perspective. Journal of Social Sciences. 2015; 11(1): 20-9. doi: 10.3844/jssp.2015.20.29.

13) Dadgaran I, Parvizy S, Peyrovi H. A global issue in nursing students' clinical learning: the theory-practice gap. Procedia-Social and Behavioral Sciences. 2012; 47: 1713-8. doi: 10.1016/j.sbspro.2012.06.888.

14) Scully NJ. The theory-practice gap and skill acquisition: An issue for nursing education. Collegian. 2011; 18(2): 93-8. doi: 10.1016/j.colegn.2010.04.002. PMID: 21706997.

15) Carina Berterö R. Reflection in and on nursing practices-how nurses reflect and develop knowledge and skills during their nursing practice. International Journal of Caring Sciences. 2010; 3(3): 85-90.

16) de Swardt HC, du Toit HS, Botha A. Guided reflection as a tool to deal with the theory-practice gap in critical care nursing students. Health SA Gesondheid. 2012; 17(1): 1-9. doi: 10.4102/hsag.v17i1.591.

17) Lord SM, Prince MJ, Stefanou CR, Stolk JD, Chen JC. The effect of different active learning environments on student outcomes related to lifelong learning. International Journal of Engineering Education. 2012; 28(3): 606-20.

18) Sobral DT. An appraisal of medical students' reflection-in-learning. Med Educ. 2000; 34(3): 182-7. doi: 10.1046/j.1365-2923.2000.00473.x. PMID: 10733703.

19) Cheraghi MA, Salasli M, Ahmadi F. Factors influencing the clinical preparation of BS nursing student interns in Iran. Int J Nurs Pract. 2008; 14(1): 26-33. doi: 10.1111/j.1440-172X.2007.00664.X. PMID: 18190481.

20) Pazokian M, Rassouli M. Challenges of nursing clinical education in world. Journal of Medical Education Development. 2012; 5(8): 18-26.

21) Heydari A, Alizadeh B, Mazloum S. The effect of preceptorship program on clinical skills of undergraduate nursing students. Iranian Journal of Medical Education. 2013; 13(7): 588-600.

22) Speziale HS, Streubert HJ, Carpenter DR. Qualitative research in nursing: Advancing the humanistic imperative. Lippincott Williams \& Wilkins; 2011.

23) Fernández-Peña R, Fuentes-Pumarola C, Malagón-Aguilera MC, Bonmatí-Tomàs A, Bosch-Farré C, Ballester-Ferrando D. The evaluation of reflective learning from the nursing student's point of view: A mixed method approach. Nurse Educ Today. 2016; 44: 59-65. doi: 10.1016/j.nedt.2016.05.005. PMID: 27429330 . 
24) Branch Jr WT, Paranjape A. Feedback and reflection: teaching methods for clinical settings. Acad Med. 2002; 77(12): 1185-8. doi: 10.1097/00001888-200212000-00005. PMID: 12480619.

25) Tsingos-Lucas C, Bosnic-Anticevich S, Schneider CR, Smith L. The effect of reflective activities on reflective thinking ability in an undergraduate pharmacy curriculum. Am J Pharm Educ. 2016; 80(4): 65. doi: 10.5688/ajpe80465. PMID: 27293232, PMCID: PMC4891863.

26) Amini A, Bilan N, Ghasempour M. Effects of Reflection on Clinical Learning of Medical Students. International Journal of Pediatrics. 2015; 3(2): 39-44. doi: 10.22038/ijp.2015.3944.

27) Yuek Ming H, Manaf LA. Assessing learning outcomes through students' reflective thinking. ProcediaSocial and Behavioral Sciences. 2014; 152: 973-7. doi: 10.1016/j.sbspro.2014.09.352.

28) Ayazgök B, Aslan H. The Review of Academic Perception, Level of Metacognitive Awareness and Reflective Thinking Skills of Science and Mathematic University Students. Procedia-Social and Behavioral Sciences. 2014; 141: 781-90. doi: 10.1016/j.sbspro.2014.05.137.

29) Mcmanus J. A new wave of sensation: The critical role emotions play in critical reflection. Presentation OLKC Making Waves Conferenc. 2011.

30) Kitchen S. An appraisal of methods of reflection and clinical supervision. Br J Theatre Nurs. 1999; 9(7): 313-7. PMID: 10614200.

31) Metzirow J. Fostering critical reflection in adulthood. Jossey-Bass Higher Education Series. 1990.

32) Vince R. Power and emotion in organizational learning. Human Relations. 2001; 54(10): 1325-51. doi: $10.1177 / \mathrm{a} 019197$.

33) Rogers RR. Reflection in higher education: A concept analysis. Innovative higher education. 2001; 26(1): 37-57. doi: 10.1023/A: 1010986404527.

34) Pai HC. An integrated model for the effects of self-reflection and clinical experiential learning on clinical nursing performance in nursing students: A longitudinal study. Nurse Educ Today. 2016; 45: 156-62. doi: 10.1016/j.nedt.2016.07.011. PMID: 27518178.

35) Okuda R, Fukada M. Changes resulting from reflection dialogues on nursing practice. Yonago acta med. 2014; 57(1): 15-22. doi: 10.1111/j.1468-5914.1986.tb00078.x. PMID: 25067874, PMCID: PMC4110690.

36) Mamede S, Schmidt HG, Penaforte JC. Effects of reflective practice on the accuracy of medical diagnoses. Med educ. 2008; 42(5): 468-75. doi: 10.1111/j.1365-2923.2008.03030.x. PMID: 18412886.

37) Iglesias GJ, Frutos MM, Casado VI, Alvarez RF, Cepeda RC, Calle LL. To innovate the practical nurse; focus based on professional competencies (I). Rev Enferm. 2005; 29(7-8): 9-12. PMID: 16989078.

38) Aiken LH, Clarke SP, Sloane DM, Lake ET, Cheney T. Effects of hospital care environment on patient mortality and nurse outcomes. J Nurs Adm. 2008; 38(5): 223-9. doi: 10.1097/01.NNA.0000312773.42352.d7. PMID: 18469615, PMCID: PMC2586978.

39) Needleman J, Buerhaus P, Mattke S, Stewart M, Zelevinsky K. Nurse-staffing levels and the quality of care in hospitals. N Engl J Med. 2002; 346(22): 1715-22. doi: 10.1056/NEJMsa012247. PMID: 12037152.

40) Hojati F, Mohmmad Davoudi A. Investigation the role of Context Support in moderating the effects of reflection on Learning Teams' Effectiveness in nursing students. Journal of Nursing Education. 2016; 5(1): 44-52.

41) McGlinn EP, Chung KC. A pause for reflection: incorporating reflection into surgical training. Ann Plast Surg. 2014; 73(2): 117-20. doi: 10.1097/SAP.0000000000000295. PMID: 25003410, PMCID: PMC4260800.

42) Dewey J. How We Think: A Ristatement of the Relation of Reflective Thinking Yo the Educative Process: DC Heath and Company; 1933. 